\title{
Recurrent Ovarian Mucinous Adenocarcinoma
}

National Cancer Institute

\section{Source}

National Cancer Institute. Recurrent Ovarian Mucinous Adenocarcinoma. NCI Thesaurus.

Code C153616.

The reemergence of ovarian mucinous adenocarcinoma after a period of remission. 